\title{
Carotid Body Paraganglioma
}

National Cancer Institute

\section{Source}

National Cancer Institute. Carotid Body Paraganglioma. NCI Thesaurus. Code C2932.

A benign or malignant extra-adrenal parasympathetic parag ang lioma arising from parag ang lia adjacent to or in the bifurcation of the common carotid artery. Most patients present with a slow growing, painless mass in the neck. 